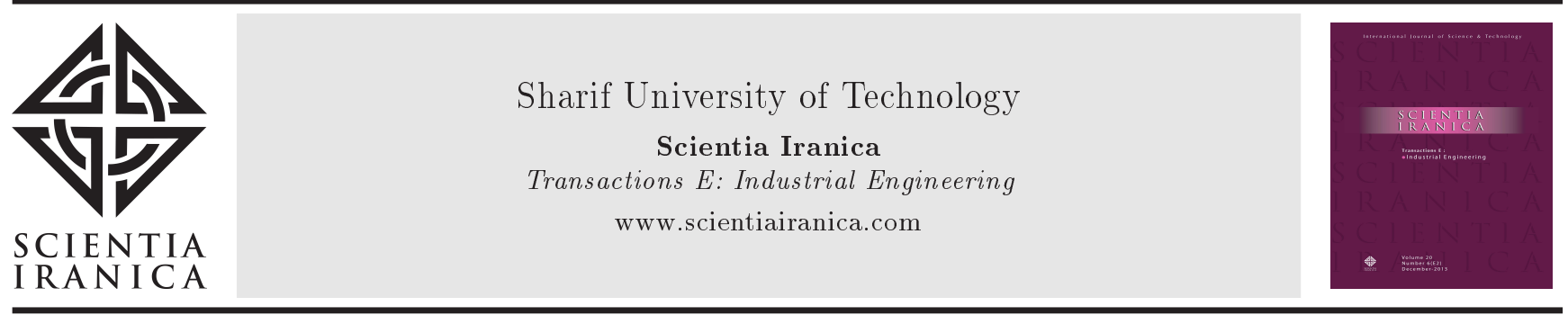

\title{
A framework for performance evaluation of energy supply chain by a compatible network data envelopment analysis model
}

\author{
S. Shafiei Kaleibari ${ }^{a}, *$, R. Gharizadeh Beiragh ${ }^{b}$, R. Alizadeh ${ }^{c}$ and M. Solimanpur \\ a. Department of Industrial Engineering, Payam Nour University, Tabriz, Iran. \\ b. Department of Industrial Engineering, Urmia University of Technology, Urmia, Iran. \\ c. Technology Foresight Group, Department of Management Science and Technology, Amirkabir University of Technology, Tehran, \\ Iran.
}

Received 2 September 2014; received in revised form 31 May 2015; accepted 25 July 2015

\author{
KEYWORDS \\ Network Data \\ Envelopment Analysis \\ (NDEA); \\ Assurance Region \\ (AR); \\ Data Envelopment \\ Analytic Hierarchy \\ Process (DEAHP); \\ Energy supply chain; \\ Technical efficiency.
}

\begin{abstract}
Inadequate supply of energy has become one of the major problems in societies due to consumers' increasing demand. Economic growth is a key reason for the increase in the energy consumption. Although different policies can be employed for resolving this problem, optimizing the efficiency of energy suppliers can be addressed as a key policy in this regard. This paper presents an adjusted Network Data Envelopment Analysis (NDEA) model for evaluating performance of energy supply chain in Iran from production to distribution stages. Some suggestions have been proposed to optimize the performance of the energy supply chain. The NDEA model is adjusted by using Assurance Region (AR) to achieve more realistic and scientific results. Borders of the assurance region obtained from Data Envelopment Analytic Hierarchy Process (DEAHP) method are entered into the NDEA model. The results obtained from this model are compared with those of conventional NDEA and technical efficiency in pairs. Finally, the Spearman and Kendall'sTau correlation tests are used for validating the results.
\end{abstract}

(C) 2016 Sharif University of Technology. All rights reserved.

\section{Introduction}

There are several ways to meet the growing demands of energy and to achieve sustainable economic growth, such as rising energy generation, utilizing advanced technologies, and so forth. However, considering high energy intensity in Iran [1,2], improving the energy efficiency can be considered as a cost-effective way to tackle this issue. The first and necessary step for optimizing the efficiency is to measure the cur-

\footnotetext{
*. Corresponding author. Tel.: +98 4135557489;

Fax: +984135557489

E-mail addresses: sin_shin_88@yahoo.com (S. Shafiei

Kaleibari); ramin.gharizadeh@ine.uut.ac.ir (R. Gharizadeh

Beiragh); rezaalizadeh@aut.ac.ir (R. Alizadeh);

m.solimanpur@urmia.ac.ir (M. Solimanpur)
}

rent efficiency level of units to identify the inefficient units. Identifying the most efficient units enables the decision makers to ascertain how inefficient units, with similar structures and goals, cannot yield the same outputs. Energy efficiency can be considered in different stages; the highest increase in performance will be achievable throughout the supply chain of energy. Having efficient systems and optimal use of resources can prevent losses and wastes. Therefore, a slight increase in performance will result in significant savings. Many studies have been conducted in this area to achieve such important goals. In order to estimate the index, Zhou et al. [3] measured economy-wide energy efficiency performance of a sample of OECD by the Shephard energy distance function to define an energy efficiency index and to adopt stochastic frontier 
analysis technique. Hu et al. [4] applied the fourstage DEA procedure to calculate energy efficiency of 23 regions in Taiwan from 1998 to 2007. Wang et al. [5] adopted the framework of total factor energy efficiency index to determine the discrepancy of energy efficiency in Chinese industrial sector based on the provincial statistical data of industrial enterprises in 30 provinces from 2005 to 2009. To evaluate the performance of 29 Electricity Distribution Divisions of Uttarakhand province, Yadav et al. [6] used DEA input-oriented model. They calculated technical and scale efficiency of their decision units. In addition, they showed that the highest inefficiency of the units is related to their scale inefficiency rather than the technical one. See and Coelli [7] calculated the technical efficiency of thermal power plants of Malaysia using stochastic frontier analysis method from 1998 to 2005. They demonstrated that ownership, plant size, and fuel type have a significant effect on technical efficiency. Alizadeh et al. [8] analyzed Iran's contribution in energy efficiency and the environmentally friendly projects supported by United Nations. Jaraitè and Di Maria [9] used DEA model to measure environmental efficiency and productivity for enhancing the performance of the overall EU electricity production in Europe during 1996 to 2007. They also analyzed changes in productivity and efficiency using econometric techniques. Solmes in [10], explained the electrical industry and consumer of energy supply chain by decomposing them into their components. Solmes showed how integration of these systems results in energy saving. In other parts of this book, the reason for inefficiency of supply chain system and the increasing costs have been described. Omrani et al. [11] presented an integrated Data Envelopment Analysis (DEA), Corrected Ordinary Least Squares (COLS), Stochastic Frontier Analysis (SFA), Principal Component Analysis (PCA), and Numerical Taxonomy (NT) algorithm for performance assessment, optimization and policy making of 38 electricity distribution units in Iran. Fallahi et al. [12] made changes in terms of technical efficiency and productivity in 32 power management companies in Iran during 2005 to 2009 using a DEA model, and subsequently, verified the stability of their DEA model by a stability test. Vazhayil and Balasubramanian [13] discussed some strategies grouped into three portfolios; namely, power generation mix, demand side efficiency group, and supply side efficiency group. Moreover, an optimization model was used for cost, risk, and barrier reduction. this portfolio, subsequently, was combined with higher-level portfolios including economic growth, energy equity, energy security, and climate sustainability. Finally, optimization is done using DEA method, and the results were compared. Pardo Martínez [14] measured energy efficiency development in non-energy-intensive sectors in Germany and Colombia according to a production-based theoretical framework using DEA from 1998 to 2005. He compared performance efficiency of the energy sector in Germany and Colombia at two aggregation levels, and then offered alternatives for improving the existing situation. Liang et al. [15] reviewed general equilibrium impact on improving energy end-use efficiency on China's economy, energy use, and $\mathrm{CO}_{2}$ emissions in 2002. To do so, they developed a static, multi-sector computable general equilibrium model. Bas [16] proposed a hybrid approach by AHP method, combined with SWOT-fuzzy TOPSIS, to formulate strategies with higher priorities for electricity supply chain in Turkey. Huang et al. [17] calculated cost efficiency and optimal scale of Taiwan's electricity distribution industry in short and long terms. The 24 units of distribution were studied using stochastic meta-frontier method during 1997 to 2002, and deregulation of the electricity distribution industry was analyzed.

Results of performance measurements and benchmarking methods help systems to detect inefficiency in their subunits and to improve the efficiency of entire units as well as entire supply chain. One of the most widely used methods for performance measurement is Data Envelopment Analysis (DEA), which is an approach based on linear programming developed by Charnes et al. [18]. Classical method of DEA in the performance evaluation of network and multi-step systems does not function properly as all these systems are considered as a whole; i.e. each Decision Making Unit (DMU) is considered as a black box in which interactions of subunits within the system are ignored. Briefly, calculations are limited to initial inputs and final outputs. To overcome this problem, NDEA was provided as a network DEA by Färe and Grosskopf [19] for the first time. Unlike traditional models, these models do not have a formula and are defined based on the type and structure of their networks. This method can, in addition, show the interaction between the internal processes and compute the overall efficiency and efficiency of the subsystems. In recent years, extensive studies have been conducted to overcome the drawbacks of the classic DEA, and different solutions have been proposed. Castelli et al. [20] evaluated the effectiveness of specific and interdependent subunits for making larger decision-making units. Lewis and Sexton [21] offered a model in which units included a network of linked subunits, where some of the subunits produced resources for other subunits, and other produced resources were consumed by other subunits. They formulated NDEA model for the structure of their outputs and inputs. Prieto and Zofío [22] evaluated technical efficiency by comparing appropriate technologies of different economies, meanwhile by considering 
an analytical framework, they let the input-output models to be regarded as a network. This network of inputs and outputs was optimized using production efficiency measures. They, additionally, implemented an input-output model for OECD countries with a network data envelopment analysis. Bai-Chen et al. [23] obtained China's energy system efficiency in both economic and environmental aspects using NDEA, and showed that form of production has a significant impact on environmental performance. Chen and Yan [24] presented three NDEA models for evaluating supply chain performance, which consider the internal structure of supply chain and their interactions simultaneously. They calculated losses of internal sources in the supply chain. Kao [25] offered a relational NDEA that considered the interactions within the system. With the idea of defining a dummy process, the primary network could become a series network in which each of the series is considered as a parallel structure. Kao and Hwang [26] assessed the effect of IT on organizational performance in banking industry using an NDEA model. Tone and Tsutsui [27] proposed a slacks-based network DEA model, called network SBM, which could deal with intermediate products. This model can evaluate divisional and the overall efficiency of decision-making units. Hsieh and Lin [28] used a model of NDEA to evaluate efficiency and effectiveness of international hotels in Taiwan considering internal interactions. Moreover, they suggested some ways for increasing the efficiency of their performance. Matthews [29] examined risk management of China's banks and divided units to environmental and organizational risk management. These units were, subsequently, entered as intermediate products into the NDEA model to calculate the amount of income efficiency. Zhao et al. [30] presented a model for evaluating a downtown space reservation based on NDEA. Input of this model is obtained using traffic microscopic simulation data. Finally, results were compared and evaluated using those of radial and slacks-based network DEA models to validate the model.

As there are many differences between entities related to energy supply chain, a comprehensive evaluation that considers all these entities simultaneously in national scale is very challenging; there has not been notable study in this instance. This tool is mainly required for authorities of energy industry to evaluate and analyze the whole energy supply chain at the same time. A desired model for this purpose should yield summarized and integrated results, which facilitates decision making for managers and authorities as well as performing effective optimization. Therefore, in this paper, we aim to develop a model for evaluating energy supply chain including production, transmission, and distribution stages simultaneously by considering all the interactions and relations throughout the supply chain stages. The model, additionally, has the ability to show which changes should be taken for inefficient units to make them efficient. However, the real optimization will be achievable mainly by the discretion of upper level managers with the aid of these directions. The model proposed for this purpose is a compatible Network Data Envelopment Analysis, and the case study for practical implementation is Iran's energy supply chain during 2007 to 2011 in dealing with seventeen basic indices. The considered indices for production stage are the cost of fuel and labor as inputs, and the generated energy as output. For transmission stage, the inputs are the station capacity, the length of transmission lines, the imported energy from neighboring power companies, the labor and the delivered energy to this section; and the outputs are energy losses, exported energy, and the energy delivered to distribution companies. Finally, in distribution stage, the input is the delivered energy from this stage, and the outputs are the sold energy and the number of customers.

In DEA model, the obtained optimal weights totally depend on the amount and pattern of data and this characteristic sometimes leads to assigning unreasonable weights to some indices. Consequently, the obtained efficiency values sometimes have a gap with reality. DEA does not consider how much an input or output is important for decision makers; it merely assigns weights in a way that enhances the output-input rate. This fact implies the objectiveness of DEA. The results obtained by objective method are based on the values of data and their distribution. To prevent obtaining objective results and utilizing experts' viewpoint, assurance region can be applied in the DEA model. It leads to achieve more realistic results. In addition, it prevents DEA model from assigning irrational weights to indices, which are important for experts. Therefore, the results will be both subjective and objective. In addition, assurance region brings about more discriminative results.

In order to enter assurance region into DEA model, it is necessary to calculate the bounds for weights. For this propose, there are several methods for obtaining priorities in AHP. Wang et al. [31] used a DEA model with the assurance region known as DEA/AR to overcome limits of DEAHP method such as illogical local weights, high insensitivity to some comparisons, and the loss of data. They, first, introduced the method of DEAHP, next provided a numerical example to discuss weaknesses of this method in terms of calculating weights of DEA models. In another article, to solve the problems of the previous article, Wang and Chin [32] proposed a new method of DEA to set priorities in the AHP, and developed it for grouped AHP. This model obtained the best weights of indices 
from paired comparisons matrix. In this method, compatibility or incompatibility is not important, and both cases result in optimal weights. In this paper, the two ways developed by Wang and Chin have been explained and the last one is applied to the model for obtaining the weights. Obtained weights have been entered into the NDEA model as upper bounds of assurance region. In the next step, the efficiency values were computed first by using conventional NDEA, and then by bounded NDEA. Subsequently, to compare the results of these two methods, results of technical efficiency were used. Technical efficiency is defined as the ratio of weighted outputs to weighted inputs in which weights were obtained by the method of Wang and Chin [32]. The results were analyzed and their correlation was compared in pairs by Spearman and Kendal's-Tao correlation tests in order to verify and validate the results. Finally, some points are suggested in the case of optimization by analyzing amounts of slack and surplus values.

\section{Methodology}

\subsection{Technical efficiency as output to input ratio}

Efficiency index in units that include one input $(x)$ and one output $(y)$ is defined as $\frac{y}{x}$; if multiple inputs and outputs exist in a unit or organization, coefficients should be allocated to inputs and outputs. Inputs have different effects on making outputs. Therefore, they should be selected according to their coefficients. Technical efficiency can be defined as the ratio of weighted outputs to weighted inputs as addressed by Cooper et al. [33]. This index is expressed as follows:

$$
T E_{j}=\frac{u_{1} y_{1 j}+u_{2} y_{2 j}+\cdots+u_{n} y_{n j}}{v_{1} x_{1 j}+v_{2} x_{2 j}+\cdots+v_{m} x_{m j}}=\frac{\sum_{r=1}^{n} u_{r} y_{r j}}{\sum_{s=1}^{m} v_{s} x_{s j}},
$$

where ' $x$ ' and ' $y$ ' are inputs and outputs, ' $v$ ' and ' $u$ ' are weights of inputs and outputs, respectively, ' $m$ ' is the number of inputs, ' $n$ ' is the number of outputs and ' $j$ ' represents $j$ th DMU. In this study, weights of inputs and outputs are obtained using Wang and Chin's method [28]. Thus, the weights of inputs, outputs, and obtained efficiency scores are consistent and reliable. Efficiency scores obtained by Eq. (1) is a basis for comparing the results of other methods.

\subsection{Network data envelopment analysis}

Network DEA has two overall structures: series and parallel. In a decision-making unit, when different parts of activities are placed along with each other, the system is series. In this case, total inputs of system enter from the first part, and the final outputs exit from the end. However, in parallel networks, all processes within the system have a parallel structure. Using these two structures, Kao [25] developed models for evaluating network decision-making, which were defined based on multiplying efficiency of subunits. The supply chain of this paper is a combination of both types of structures.

\subsection{DEA/AR model}

In order to avoid obtaining zero values for defined indexes' weights (weights of outputs and inputs for case), there should be some boundaries for optimal weights $\left(v_{i}^{*}, u_{j}^{*}\right)$ in DEA model. This will result in an efficiency score for each DMU in which all indexes have effects on the obtained score, and none of them gets zero weight in calculation of the efficiency score. This is the reason that leads to the emergence of assurance region, which relatively limits the amount of assigned weights. In this paper, the model developed by Wang and Chin [32] is used to get the upper bounds of weights in NDEA. Let:

$$
A=\left(a_{i j}\right)_{n \times n}=\left[\begin{array}{cccc}
a_{11} & a_{12} & \cdots & a_{1 n} \\
a_{21} & a_{22} & \cdots & a_{2 n} \\
\vdots & \vdots & \cdots & \vdots \\
a_{n 1} & a_{n 2} & \cdots & a_{n n}
\end{array}\right]
$$

be a pair-wise comparison matrix (obtained according to experts' opinions) in which $a_{i j}$ is the importance of $i$ th index versus $j$ th index with $a_{i i}=1$, and $a_{j i}=1 / a_{i j}$ and $W=\left(w_{1}, \cdots, w_{n}\right)^{T}$ is the priority vector. Hereafter, algorithm for calculating weights is different from standard AHP method. In DEAHP, each row of the matrix $A$ is presented as a DMU and each column is presented as an output, which assumes a dummy value of one as input for all DMUs. Each DMU has, therefore, an output and one dummy constant input based on which the following inputoriented CCR model is constructed to estimate local priorities (weights) of the pair-wise comparison matrix A:

$$
\max w_{1}=\sum_{j=1}^{n} a_{1 j} v_{j},
$$

subject to:

$$
\begin{array}{ll}
u_{1}=1, & \\
\sum_{j=1}^{n} a_{i j} v_{j}-u_{1} \leq 0, & i=1, \ldots, n, \\
u_{1}, v_{j} \geq 0, & j=1, \cdots, n .
\end{array}
$$

In the above model, $w_{1}$ shows efficiency score for DMU1 (first row of matrix) which is the final weight that 
can be used instead of AHP priority weight for first index. For each row, Model (3) is computed and run as a DMU. However, final weights of indexes $w^{*}=$ $\left(w_{1}^{*}, \cdots, w_{n}^{*}\right)^{T}$ are calculated by Model (3) if pair-wise comparison matrix $A$ is fully consistent.

Wang and Chin (2009) [28] showed that Model (3) can sometimes be in conflict with inconsistent pair-wise comparison matrix. To overcome the shortcomings of DEAHP, they developed a method of DEA to determine priorities in AHP, which produced true weights for the perfectly consistent pair-wise comparison matrix. It, additionally, could produce the best local priorities for inconsistent pair-wise comparison matrix that were logical and consistent with the subjective judgments of decision-makers. The proposed model is as follows:

$$
\operatorname{maximize} \quad w_{1}=\sum_{j=1}^{n} a_{1 j} v_{j},
$$

subject to:

$$
\begin{aligned}
& \sum_{j=1}^{n}\left(\sum_{i=1}^{n} a_{i j}\right) v_{j}=1, \\
& \sum_{j=1}^{n} a_{i j} v_{j} \geq n v_{i}, \quad i=1, \cdots, n, \\
& v_{j} \geq 0, \quad j=1, \cdots, n .
\end{aligned}
$$

Solving the above linear programming model for each $w_{i}$ will yield the best weight for each index or choice. In this paper, to obtain upper bounds of weights for NDEA, Model (4) is used. Therefore, entering experts' viewpoint led to preventing unrealistic DMU efficiency.

\section{Case study}

Generally, energy supply chain includes generation and distribution. Manufacturing power plants generate electricity and distribution companies distribute the generated electricity among consumers. In this chain, plants (regardless of the generating way) are considered as energy suppliers for the distribution section. In a similar way, distribution companies are electricity suppliers for consumers. Electricity generation and delivering have great complexity in the supply chain due to the climatic conditions and geographical specifications of the area. Regional power companies in Iran, which are responsible for electricity production and delivery to distribution companies, have similar goals, missions, tasks, and activities. The difference is often in the volume of activities, the extent of geography, and the overall structure of companies which will follow the same structural pattern.

\subsection{First part of supply chain structure: Regional electricity generation companies}

The prinicipal part of power industry is power generation section. Management of regional electricity companies is responsible for constructing new power plants as well as maintaining and monitoring old ones.

\subsection{Second part of supply chain structure: Regional power transmission companies}

The location of electricity power plants is determined considering various technological, economic, and social factors such as fuel, water, and the distance to the residential areas (to prevent environmental pollution). Consequently, a standard distance is considered usual in terms of locating power plants, and it should be supported by transmission lines, which act as suppliers of power for consumption centers. In addition, transmission establishment is necessary for increasing or decreasing voltage and making adjustment with the centers of generation and consumption. In brief, the electricity generated by power plants is delivered to the distribution network by transmission facilities including posts and transmission lines.

\subsection{Third part of supply chain structure: Power distribution companies}

Distribution of power is the link between the power industry and customers, and has multiple roles; first, supplies consumers and sells electricity as an economic goods; second, has a vital technical role in maintaining, operating, and developing the distribution networks; third, maintains communication and coordination with the upstream sectors of energy supply chain. Considering the above description, Iran's electric power supply chain network was designed, in this paper, as follows.

System 1 shows the regional power company and System 2 shows the electricity distribution network. The way that this network has been developed is based on the level of independency in the case of management. Obviously, the three major sections are independent in many fields as well as in management. However, for example, in distribution section, despite similarities between distribution subsystems, they were assigned to private organizations with different policies and management methods. Therefore, it is necessary to compare them with each other in order to find the weaknesses and strengths of each one. There are 16 active regional power companies in Iran that all have been evaluated in this paper. Inputs and outputs of this network were considered according to Iran's Ministry of Energy efficiency, and are presented as follows:

$\begin{array}{ll}z_{1 j 0} & \text { Cost of fuel; } \\ z_{2 j 0} & \text { Labor of generation section; } \\ z_{1 j 1} & \text { Generated energy; }\end{array}$




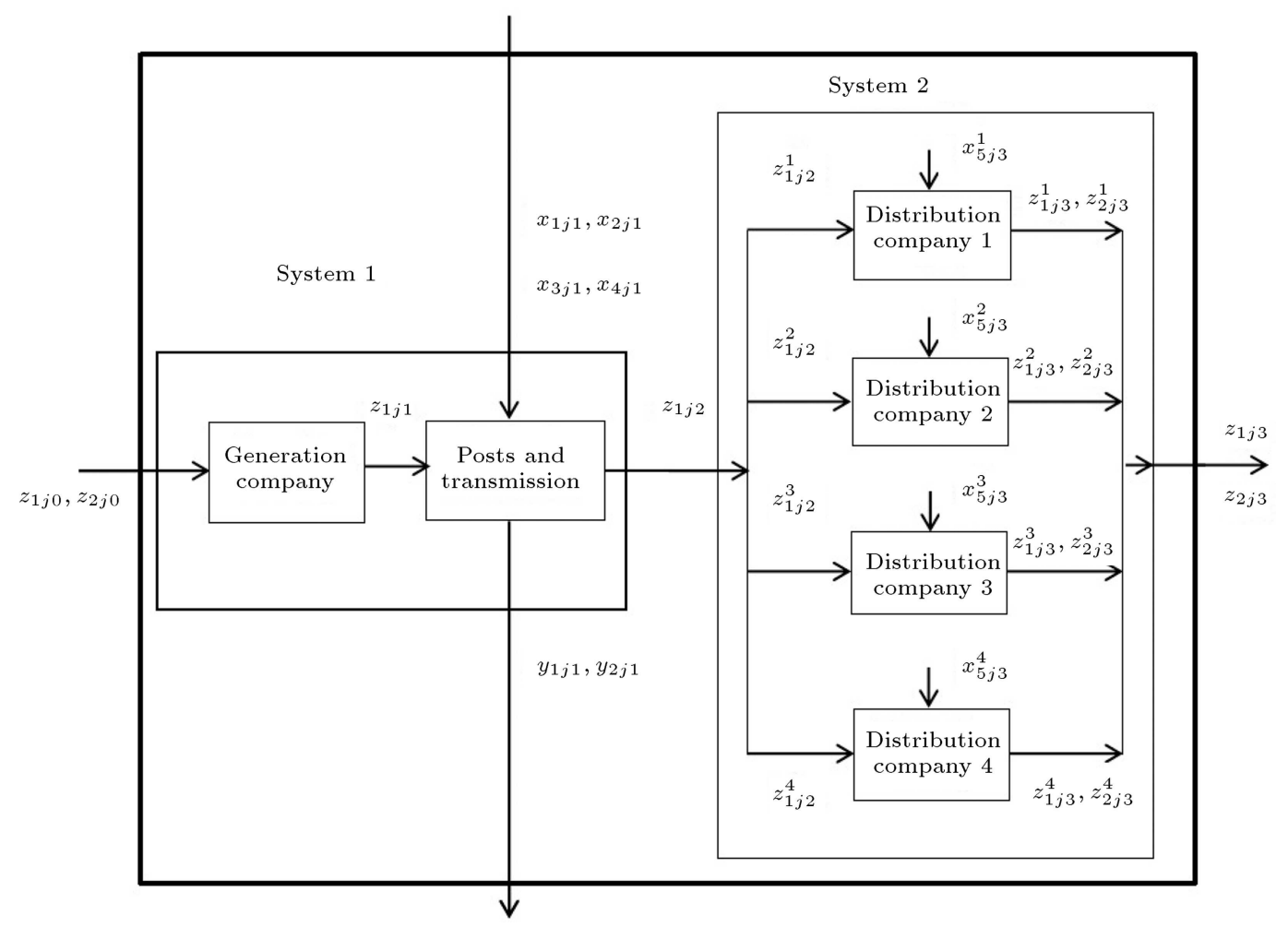

Figure 1. The energy supply chain network in Iran.

$z_{1 j 2} \quad$ Delivered energy to distribution section;

$z_{1 j 2}^{1} \quad$ Energy delivered to the first distribution company;

$z_{1 j 2}^{2} \quad$ Energy delivered to the second distribution company;

$z_{1 j 2}^{3} \quad$ Energy delivered to the third distribution company;

$z_{1 j 2}^{4} \quad$ Energy delivered to the fourth distribution company;

$x_{1 j 1} \quad$ Total station's capacity (mega volt ampere);

$x_{2 j 1} \quad$ Length of transmission lines;

$x_{3 j 1} \quad$ Imported energy from neighboring power companies;

$x_{4 j 1} \quad$ Labor of transmission section;

$x_{5 j 1} \quad$ Labor of distribution section;

$y_{1 j 1}$

$y_{2 j 1}$

$z_{1 j 3}$

$z_{2 j 3}$

\section{Energy losses of transmission;}

Exported energy to nearby companies;

Total sold energy;

Number of customers.

All indexes of distribution section, i.e. labor, total sold energy, and number of customers, are defined separately for each of the parallel subsystems of this section. Energy losses of transmission index $\left(y_{1 j 1}\right)$ is an undesirable output, and lower values for this index are more desirable for decision-makers. Since the objective function in this study was to maximize output, the original values for $y_{1 j 1}$ were converted to $\left(y_{1 j 1}\right)^{-1}$ for maximizing it, which is desired for this index.

In Figure 1, the second system of supply chain has parallel subsystems. The number of subsystems (distribution companies) is not the same in all DMUs and according to the data, each DMU may have 1, 2, 3, or 4 subsystems as distribution companies. Therefore, the mark "-" is used for some units to indicate the absence of subsystem for distribution section of that DMU. The raw data of this case study belongs to a five-year period from 2007 to 2011, which have not been brought for saving space. Due to the increasing number of indexes compared to the number of DMUs, thus reducing discriminative power of NDEA, these data were used as time series for five consecutive years. In fact, each year is considered as one DMU for regional electricity companies. Therefore, the total number of DMUs in this article is 80 . Finally, the mean values of efficiency of regional power company in the past five years are considered as the company's efficiency score for analyzing the results.

\section{Modeling the designed network}

According to the descriptions, a comprehensive model, which is a combination of series and parallel structures model, is presented. Iran's energy supply chain net- 
Table 1. Weights of indexes.

\begin{tabular}{|c|c|c|c|c|c|c|c|c|c|c|c|c|}
\hline$z_{1 j 0}$ & $z_{2 j 0}$ & $z_{1 j 1}$ & $x_{1 j 1}$ & $x_{2 j 1}$ & $x_{3 j 1}$ & $x_{4 j 1}$ & $x_{5 j 3}$ & $y_{1 j 1}$ & $y_{2 j 1}$ & $z_{1 j 2}$ & $z_{1 j 3}$ & $z_{2 j 3}$ \\
\hline 0.1837 & 0.0167 & 0.2280 & 0.1418 & 0.0225 & 0.0283 & 0.0381 & 0.0104 & 0.0127 & 0.088 & 0.0470 & 0.1146 & 0.0682 \\
\hline
\end{tabular}

work can be defined as follows:

$$
E_{k}=\max \sum_{\substack{l \in l_{p} \\ p=3}} w_{l p} z_{l k p}+\sum_{\substack{r=1 \\ p=1}}^{2} u_{r} y_{r k p}
$$

s.t.

$$
\begin{gathered}
\sum_{\substack{l \in l_{p} \\
p=0}} w_{l p} z_{l k p}+\sum_{\substack{i=1 \\
p=1}}^{5} v_{i} x_{i k p}=1 \\
\left(\sum_{\substack{l \in l_{p} \\
p=3}} w_{l p} z_{l j p}+\sum_{\substack{r=1 \\
p=1}}^{2} u_{r} y_{r j p}\right) \\
-\left(\sum_{\substack{l \in l_{p} \\
p=0}} w_{l p} z_{l j p}+\sum_{\substack{i=1 \\
p=1}}^{5} v_{i} x_{i j p}\right) \leq 0
\end{gathered}
$$$$
j=1, \cdots, 80
$$

$$
\left(\sum_{\substack{l \in l_{p} \\ p=3}} w_{l p} z_{l j p}\right)-\left(\sum_{\substack{l \in l_{p} \\ p=2}} w_{l p} z_{l j p}\right) \leq 0 \quad j=1, \cdots, 80
$$

$w_{13} z_{1 j 3}^{1}+w_{23} z_{2 j 3}^{1}-w_{12} z_{1 j 2}^{1} \leq 0 \quad j=1, \cdots, 80$, $w_{13} Z_{1 j 3}^{2}+w_{23} Z_{2 j 3}^{2}-w_{12} z_{1 j 2}^{2} \leq 0 \quad j=1, \cdots, 80$, $w_{13} z_{1 j 3}^{3}+w_{23} z_{2 j 3}^{3}-w_{12} z_{1 j 2}^{3} \leq 0 \quad j=1, \cdots, 80$, $w_{13} z_{1 j 3}^{4}+w_{23} z_{2 j 3}^{4}-w_{12} z_{1 j 2}^{4} \leq 0 \quad j=1, \cdots, 80$,

$$
\begin{gathered}
\left(\sum_{\substack{l \in l_{p} \\
p=2}} w_{l p} z_{l j p}+\sum_{\substack{r=1 \\
p=1}}^{2} u_{r} y_{r j p}\right) \\
-\left(\sum_{\substack{l \in l_{p} \\
p=1}} w_{l p} z_{l j p}+\sum_{\substack{i=1 \\
p=1}}^{5} v_{i} x_{i j p}\right) \leq 0
\end{gathered}
$$$$
j=1, \cdots, 80,
$$$$
\left(\sum_{\substack{l \in l_{p} \\ p=1}} w_{l p} z_{l j p}\right)-\left(\sum_{\substack{l \in l_{p} \\ p=0}} w_{l p} z_{l j p}\right) \leq 0
$$

$$
\begin{array}{r}
j=1, \cdots, 8, \\
u_{r}, v_{i}, w_{l p} \geq 0,
\end{array}
$$

where:

$z_{l j p} \quad l$ th input or output of $p$ th step for $\mathrm{DMU}_{j}$;

$w_{l p} \quad$ Attributed weight in model;

$y_{r j p} \quad r$ th output of $p$ th step for $\mathrm{DMU}_{j}$;

$u_{r} \quad$ Attributed weight in model;

$x_{i j p} \quad i$ th input of $p$ th step for $\mathrm{DMU}_{j}$;

$v_{i} \quad$ Attributed weight in model;

$x_{i j p}^{t} \quad i$ th input of $t$ th electricity distribution company in $p$ th step for $\mathrm{DMU}_{j}$;

$v_{i} \quad$ Attributed weight in model.

To enter assurance region into Model (5), weights derived from Model (4) are used. These weights are given in Table 1.

By entering these weights as upper bounds, the final NDEA/AR model is obtained. Therefore, by taking into account the assurance region, NDEA model is defined as follows:

$$
E_{k}=\max \sum_{\substack{l \in l_{p} \\ p=3}} w_{l p} z_{l k p}+\sum_{\substack{r=1 \\ p=1}}^{2} u_{r} y_{r k p}
$$

s.t.

$$
\sum_{\substack{l \in l_{p} \\ p=0}} w_{l p} z_{l k p}+\sum_{\substack{i=1 \\ p=1}}^{5} v_{i} x_{i k p}=1
$$

$$
\begin{gathered}
\left(\sum_{\substack{l \in l_{p} \\
p=3}} w_{l p} z_{l j p}+\sum_{\substack{r=1 \\
p=1}}^{2} u_{r} y_{r j p}\right) \\
-\left(\sum_{\substack{l \in l_{p} \\
p=0}} w_{l p} z_{l j p}+\sum_{\substack{i=1 \\
p=1}}^{5} v_{i} x_{i j p}\right) \leq 0
\end{gathered}
$$

$$
j=1, \cdots, 80,
$$

$$
\left(\sum_{\substack{l \in l_{p} \\ p=3}} w_{l p} z_{l j p}\right)-\left(\sum_{\substack{l \in l_{p} \\ p=2}} w_{l p} z_{l j p}\right) \leq 0
$$




$$
\begin{aligned}
& j=1, \cdots, 80, \\
& w_{13} z_{1 j 3}^{1}+w_{23} z_{2 j 3}^{1}-w_{12} z_{1 j 2}^{1} \leq 0 \quad j=1, \cdots, 80, \\
& w_{13} Z_{1 j 3}^{2}+w_{23} Z_{2 j 3}^{2}-w_{12} z_{1 j 2}^{2} \leq 0 \quad j=1, \cdots, 80, \\
& w_{13} z_{1 j 3}^{3}+w_{23} z_{2 j 3}^{3}-w_{12} z_{1 j 2}^{3} \leq 0 \quad j=1, \cdots, 80, \\
& w_{13} z_{1 j 3}^{4}+w_{23} z_{2 j 3}^{4}-w_{12} z_{1 j 2}^{4} \leq 0 \quad j=1, \cdots, 80, \\
& \left(\sum_{\substack{l \in l_{p} \\
p=2}} w_{l p} z_{l j p}+\sum_{\substack{r=1 \\
p=1}}^{2} u_{r} y_{r j p}\right) \\
& -\left(\sum_{\substack{l \in l_{p} \\
p=1}} w_{l p} z_{l j p}+\sum_{\substack{i=1 \\
p=1}}^{5} v_{i} x_{i j p}\right) \leq 0 \\
& j=1, \cdots, 80, \\
& \left(\sum_{\substack{l \in l_{p} \\
p=1}} w_{l p} z_{l j p}\right)-\left(\sum_{\substack{l \in l_{p} \\
p=0}} w_{l p} z_{l j p}\right) \leq 0 \\
& j=1, \cdots, 80, \\
& 0 \leq u_{1} \leq \text { weight } y_{1}, \quad 0 \leq u_{2} \leq \text { weight } y_{2}, \\
& 0 \leq v_{1} \leq \text { weight } x_{1}, \quad 0 \leq v_{2} \leq \text { weight } x_{2}, \\
& 0 \leq v_{3} \leq \text { weight } x_{3}, \quad 0 \leq v_{4} \leq \text { weight } x_{4}, \\
& 0 \leq v_{5} \leq \text { weight } x_{5}, \quad 0 \leq w_{10} \leq \text { weight } w_{10}, \\
& 0 \leq w_{20} \leq \text { weight } w_{20}, \quad 0 \leq w_{11} \leq \text { weight } w_{11}, \\
& 0 \leq w_{12} \leq \text { weight } w_{12}, \quad 0 \leq w_{13} \leq \text { weight } w_{13}, \\
& 0 \leq w_{23} \leq \text { weight } w_{23} .
\end{aligned}
$$

Let $u_{r}^{*}, v_{i}^{*}$ and $w_{l p}^{*}$ be the optimal multipliers obtained from running Model (6). Subsequently, the efficiency of each unit and subunit for DMUj can be defined as below:

$$
\begin{aligned}
& E_{\text {Distribution (1) }}=\left(w_{13}^{*} z_{1 j 3}^{1}+w_{23}^{*} z_{2 j 3}^{1}\right) / w_{12}^{*} z_{1 j 2}^{1} ; \\
& \quad j=1, \cdots, 80, \\
& E_{\text {Distribution (2) }}=\left(w_{13}^{*} Z_{1 j 3}^{2}+w_{23}^{*} Z_{2 j 3}^{2}\right) / w_{12}^{*} z_{1 j 2}^{2} ; \\
& \quad j=1, \cdots, 80,
\end{aligned}
$$

$$
\begin{aligned}
& E_{\text {Distribution (3) }}=\left(w_{13}^{*} z_{1 j 3}^{3}+w_{23}^{*} z_{2 j 3}^{3}\right) / w_{12}^{*} z_{1 j 2}^{3} ; \\
& j=1, \cdots, 80, \\
& E_{\text {Distribution (4) }}=\left(w_{13}^{*} z_{1 j 3}^{4}+w_{23}^{*} z_{2 j 3}^{4}\right) / w_{12}^{*} z_{1 j 2}^{4} ; \\
& j=1, \cdots, 80, \\
& E_{\text {transmition }}=\left(\sum_{\substack{l \in l_{p} \\
p=2}} w_{l p}^{*} z_{l j p}+\sum_{\substack{r=1 \\
p=1}}^{2} u_{r}^{*} y_{r j p}\right) \\
& /\left(\sum_{\substack{l \in l_{p} \\
p=1}} w_{l p}^{*} z_{l j p}+\sum_{\substack{i=1 \\
p=1}}^{5} v_{i}^{*} x_{i j p}\right) \\
& j=1, \cdots, 80, \\
& E_{\text {generation }}=\left(\sum_{\substack{l \in l_{p} \\
p=1}} w_{l p}^{*} z_{l j p}\right) /\left(\sum_{\substack{l \in l_{p} \\
p=0}} w_{l p}^{*} z_{l j p}\right), \\
& j=1, \cdots, 80 .
\end{aligned}
$$

\section{Optimization}

The optimization process presented in this article is based on the values of slack and surplus variables for indexes. As NDEA models are linear programing, they can be used to ascertain the indexes of units that should increase or decrease according to their reference sets. The inefficient units can be efficient similar to the units in their reference set, if they can produce the target values of output using the target level of inputs. The target points $\hat{x}$ and $\hat{y}$ are calculated using the following equation [34]:

$$
\left(x_{i o}, y_{r o}\right) \rightarrow\left(\underset{i o}{\hat{x}}=\theta_{o} x_{i o}-s_{i}^{-}, \hat{y}=y_{i o}+s_{r}^{+}\right) .
$$

$\theta_{o}$ is the efficiency score of DMUo that can be obtained from dual or primary model. Input slacks $\left(s_{i}^{-}\right)$indicate needed reductions in related inputs, and output slacks $\left(s_{i}^{+}\right)$represent needed increase in related outputs. The difference between the actual values and target values of inputs $\left(x_{i o}-\underset{i o}{\hat{i}}\right)$ shows the reduction, while the difference between the target values and observed values of outputs $\left(y_{i o}-\hat{y}\right)$ represents the amount of outputs to be increased in order to become efficient. 
Table 2. Obtained results from all three models.

\begin{tabular}{clcccccc}
\hline $\begin{array}{c}\text { Number } \\
\text { of } \\
\text { DMUs }\end{array}$ & $\begin{array}{c}\text { Names } \\
\text { of DMUs }\end{array}$ & Rank & $\begin{array}{c}\text { TE } \\
\text { score }\end{array}$ & Rank & $\begin{array}{c}\text { NDEA/AR } \\
\text { score }\end{array}$ & Rank & $\begin{array}{c}\text { NDEA } \\
\text { score }\end{array}$ \\
\hline 1 & Azarbaijan & 6 & 2.15117 & 3 & 0.94032 & 4 & 0.94304034 \\
2 & Esfehan & 5 & 2.16507 & 7 & 0.86361 & 10 & 0.86365540 \\
3 & Bakhtar & 12 & 1.50894 & 5 & 0.88206 & 6 & 0.88205914 \\
4 & Tehran & 1 & 3.03890 & 4 & 0.89022 & 5 & 0.89021612 \\
5 & Khorasan & 3 & 2.45168 & 9 & 0.85575 & 7 & 0.87156962 \\
6 & Khozestan & 8 & 1.86526 & 11 & 0.71051 & 12 & 0.71088064 \\
7 & Zanjan & 16 & 0.71420 & 14 & 0.59418 & 16 & 0.59529420 \\
8 & Semnan & 14 & 1.18485 & 12 & 0.67737 & 1 & 0.99103768 \\
9 & Sistan & 15 & 1.08173 & 16 & 0.43135 & 14 & 0.64821974 \\
10 & Gharb & 13 & 1.32556 & 10 & 0.81023 & 11 & 0.81817626 \\
11 & Fars & 7 & 1.87375 & 6 & 0.86433 & 8 & 0.86937146 \\
12 & Kerman & 10 & 1.57442 & 8 & 0.86359 & 9 & 0.86771844 \\
13 & Gilan & 2 & 2.76235 & 2 & 0.96927 & 3 & 0.96926506 \\
14 & Mazandaran & 4 & 2.34352 & 1 & 0.97197 & 2 & 0.97200056 \\
15 & Hormozgan & 9 & 1.78090 & 13 & 0.65127 & 13 & 0.65127320 \\
16 & Yazd & 11 & 1.53606 & 15 & 0.57184 & 15 & 0.62556984 \\
\hline
\end{tabular}

\section{Results and discussion}

Results of the three models using Lingo software are shown in Table 2.

According to NDEA principles, a system is efficient if only all its subsystems are efficient. As a result, in such a wide network, obtaining efficiency with the score of 1 is extremely unlikely. In general, it can be said that this is a frequent event in NDEA application. Thus, the criterion for judging the effectiveness of DMUs is higher scores of efficiency. The first column of Table 2 shows the number of DMUs, the second is the names of DMUs, columns 3, 5, and 7 indicate ranks of units based on three proposed models. Columns 4,6 , and 8 are efficiency scores of DMUs. In this study, the basis for ranking is the results of NDEA/AR model. Two other methods were used for comparison and validation. Results of the fifth column of Table 2 demonstrate that DMU13 and DMU14 in NDEA/AR method are the most efficient units. These units, too, achieved high efficiency scores in two other methods. In addition, according to these results, DMU9 and DMU16 are the most inefficient units while having lower efficiencies in other methods.

To verify the results of three models, nonparametric Spearman correlation test $\left(r_{s}\right)$ and Kendall's Tau correlation test $(\tau)$ were employed in SPSS Software. Table 3 reports $r_{s}$ between rankings of the models, which resulted in the rejection of $\mathrm{HO}$ at 0.01 level. Moreover, Kendall's Tau test confirmed this finding at the same level of significance.
Table 3. Correlation between models.

\begin{tabular}{lccc}
\hline & NDEA/AR & NDEA & NDEA/AR \\
& $\&$ & $\&$ & $\&$ \\
& NDEA & TE & TE \\
\hline Kendal's Tau & 0.7 & 0.42 & 0.55 \\
Spearman & 0.77 & 0.52 & 0.74 \\
\hline
\end{tabular}

According to Table 3, it can be clearly seen that the correlation rate between NDEA/AR and TE is higher than that between NDEA and TE. Furthermore, according to NDEA results (i.e. eighth column in Table 2), DMU8, DMU14 and DMU13 ranked first, second, and third, respectively, however according to NDEA/AR (i.e. seventh column), DMU14 and DMU13 ranked first and second, respectively, and DMU8 ranked 12th which indicates that DMU8 has performed poorly in the indexes important to the experts. The most important index in terms of expertise was generating energy $\left(z_{1 j 1}\right)$ and DMU8 was found very weak according to this index. These outcomes, besides the higher correlation rate, indicate that using assurance region in NDEA methods led to achieving better and more realistic results. In other words, the NDEA/AR model was effective according to the experts' viewpoints. To analyze the increasing and decreasing trends of efficiency for regional electricity companies, calculated efficiencies from NDEA/AR in the last five years are given in Table 4 .

Table 4 shows that Kerman Regional Electric Company (DMU12) and Gillan (DMU13) had the top 
Table 4. Efficiency score of NDEA/AR model.

\begin{tabular}{|c|c|c|c|c|c|c|c|c|c|c|}
\hline \multirow{2}{*}{$\begin{array}{c}\text { Names } \\
\text { of } \\
\text { DMUs }\end{array}$} & \multicolumn{2}{|c|}{2007} & \multicolumn{2}{|c|}{2008} & \multicolumn{2}{|c|}{2009} & \multicolumn{2}{|c|}{2010} & \multicolumn{2}{|c|}{2011} \\
\hline & DMUs & $\begin{array}{c}\text { Efficiency } \\
\text { scores }\end{array}$ & DMUs & $\begin{array}{c}\text { Efficiency } \\
\text { scores }\end{array}$ & DMUs & $\begin{array}{c}\text { Efficiency } \\
\text { scores } \\
\end{array}$ & DMUs & $\begin{array}{c}\text { Efficiency } \\
\text { scores }\end{array}$ & DMUs & $\begin{array}{c}\text { Efficiency } \\
\text { scores } \\
\end{array}$ \\
\hline Azarbaijan & 1 & 0.9519691 & 17 & 0.9643588 & 33 & 0.9455851 & 49 & 0.9456086 & 65 & 0.8940663 \\
\hline Esfehan & 2 & 0.9655209 & 18 & 0.9711506 & 34 & 0.8624931 & 50 & 0.8022415 & 66 & 0.7166557 \\
\hline Bakhtar & 3 & 0.8031276 & 19 & 0.9483316 & 35 & 0.9153569 & 51 & 0.8819385 & 67 & 0.8615411 \\
\hline Tehran & 4 & 0.9396117 & 20 & 0.9578501 & 36 & 0.8655095 & 52 & 0.8471559 & 68 & 0.8409534 \\
\hline Khorasan & 5 & 0.9629956 & 21 & 0.9843991 & 37 & 0.8363535 & 53 & 0.8363739 & 69 & 0.6586421 \\
\hline Khozestan & 6 & 0.8265885 & 22 & 0.712349 & 38 & 0.6234209 & 54 & 0.6159828 & 70 & 0.7742332 \\
\hline Zanjan & 7 & 0.6712896 & 23 & 0.9343764 & 39 & 0.4179298 & 55 & 0.4949085 & 71 & 0.4523897 \\
\hline Semnan & 8 & 0.8431468 & 24 & 0.5232251 & 40 & 0.9293339 & 56 & 0.639341 & 72 & 0.4517816 \\
\hline Sistan & 9 & 0.3686625 & 25 & 0.5297801 & 41 & 0.4374939 & 57 & 0.4459096 & 73 & 0.3749249 \\
\hline Gharb & 10 & 0.7657869 & 26 & 0.9261429 & 42 & 0.9078139 & 58 & 0.7387821 & 74 & 0.712618 \\
\hline Fars & 11 & 0.9762972 & 27 & 0.9444089 & 43 & 0.9585943 & 59 & 0.7749404 & 75 & 0.6674183 \\
\hline Kerman & 12 & 0.9960169 & 28 & 0.9263354 & 44 & 0.9913664 & 60 & 0.8430777 & 76 & 0.5611622 \\
\hline Gilan & 13 & 0.9093013 & 29 & 0.9944486 & 45 & 0.9944896 & 61 & 0.9946948 & 77 & 0.953391 \\
\hline Mazandaran & 14 & 0.9957679 & 30 & 0.9872864 & 46 & 0.9607612 & 62 & 0.9642231 & 78 & 0.951826 \\
\hline Hormozgan & 15 & 0.6046937 & 31 & 0.4989872 & 47 & 0.525958 & 63 & 0.7159716 & 79 & 0.9107555 \\
\hline Yazd & 16 & 0.6050259 & 32 & 0.6564377 & 48 & 0.5602491 & 64 & 0.5502185 & 80 & 0.4872815 \\
\hline
\end{tabular}

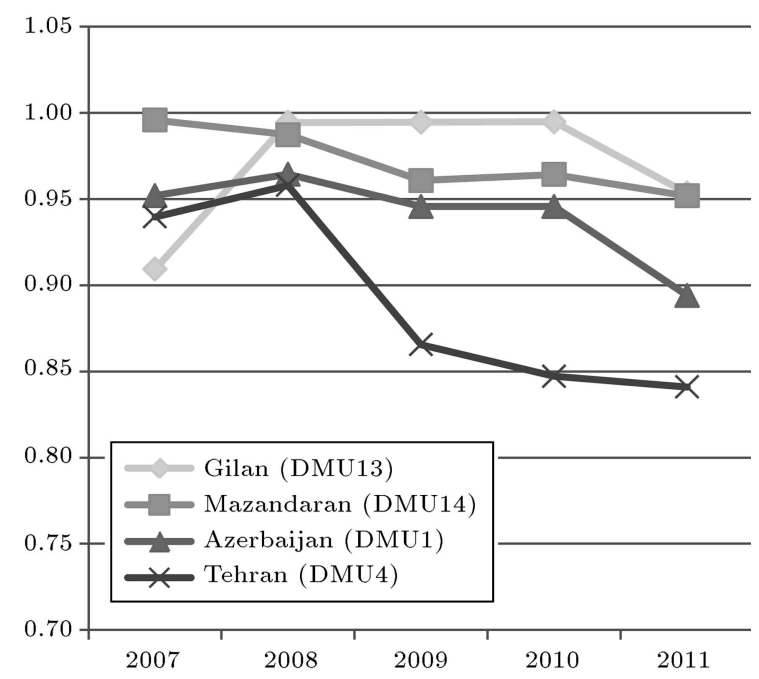

Figure 2. Efficiency comparison between four best DMUs.

performances in 2007 and during 2008-2011, respectively. For further analysis, efficiencies of the first four highly ranked regional electricity companies (DMU14, DMU13, DMU1, and DMU4) using NDEA/AR are shown in Figure 2.

According to Figure 2, during 2007 to 2011, performance of Mazandaran and Gilan companies (DMU14 and DMU13) are almost one. During five years, Mazandaran Regional Electric Company has had less variation and could get the best ranks. Moreover, it is clear from Table 4 that performance of Mazandaran Company in 2007 had the highest value (0.9957679); however, its efficiency has been reduced over time. According to Figure 2, DMU13 from 2008 to 2011 had fewer variations in terms of efficiency score. However, in 2007, it had the lowest efficiency score (0.9093013), which is the main reason for its decline in the overall efficiency scores. Nevertheless, its performance has improved since 2007, and it has been the best DMU in the recent years. Table 5 shows efficiency values calculated for subsystems of energy supply chain using Models (7) for 5 years. The second column of the table demonstrates regional electricity companies, the third column is the efficiency of generation section, the fourth column is the efficiency of transmission, and the fifth to eighth columns indicate efficiency of distribution subsystems. In this table, mark ". " implies absence of subsystems for that particular DMU; for example, Azerbaijan and Khorasan had four distribution companies, while Zanjan, Semnan, Sistan, Gilan, Yazd, and Hormozgan had only one distribution subsystem.

The third column of Table 5 shows that, in generation sector, Fars (DMU11), Gilan (DMU13), and Mazandaran (DMU14) are the most efficient units, whereas Semnan company is an inefficient DMU in generating energy. According to the fourth column, Mazandaran (DMU14), Azerbaijan (DMU1), and Gilan (DMU13) are the most efficient companies in transmitting energy, while Zanjan (DMU7) stands in the opposite point. Results from the fourth to eighth columns of distribution section show that the third subsystem of distribution section (i.e. Mazandaran 
Table 5. Efficiency of the sub-system.

\begin{tabular}{|c|c|c|c|c|c|c|c|}
\hline $\begin{array}{c}\text { Number } \\
\text { of } \\
\text { DMUs }\end{array}$ & $\begin{array}{c}\text { Name } \\
\text { of } \\
\text { DMUs }\end{array}$ & Generation & Transmission & $\begin{array}{l}\text { Distribution } \\
\text { first } \\
\text { sub-system }\end{array}$ & $\begin{array}{l}\text { Distribution } \\
\text { second } \\
\text { sub-system }\end{array}$ & $\begin{array}{c}\text { Distribution } \\
\text { third } \\
\text { sub-system }\end{array}$ & $\begin{array}{c}\text { Distribution } \\
\text { fourth } \\
\text { sub-system }\end{array}$ \\
\hline 1 & Azarbaijan & 0.639 & 0.986 & 0.448 & 0.511 & 0.953 & 0.905 \\
\hline 2 & Esfehan & 0.685 & 0.758 & 0.660 & 0.866 & 0.891 & - \\
\hline 3 & Bakhtar & 0.665 & 0.952 & 0.590 & 0.537 & 0.816 & - \\
\hline 4 & Tehran & 0.738 & 0.909 & 0.753 & 0.528 & 0.961 & - \\
\hline 5 & Khorasan & 0.754 & 0.904 & 0.667 & 0.524 & 0.792 & 0.904 \\
\hline 6 & Khozestan & 0.808 & 0.890 & 0.452 & 0.623 & 0.724 & - \\
\hline 7 & Zanjan & 0.556 & 0.675 & 0.550 & - & - & - \\
\hline 8 & Semnan & 0.439 & 0.881 & 0.522 & - & - & - \\
\hline 9 & Sistan & 0.528 & 0.823 & 0.457 & - & - & - \\
\hline 10 & Gharb & 0.707 & 0.790 & 0.778 & 0.855 & 0.800 & - \\
\hline 11 & Fars & 0.963 & 0.943 & 0.522 & 0.605 & 0.849 & - \\
\hline 12 & Kerman & 0.852 & 0.902 & 0.511 & 0.594 & - & - \\
\hline 13 & Gilan & 0.916 & 0.983 & 0.603 & - & - & - \\
\hline 14 & Mazandaran & 0.824 & 0.998 & 0.550 & 0.687 & 0.953 & - \\
\hline 15 & Hormozgan & 0.765 & 0.678 & 0.498 & - & - & - \\
\hline 16 & Yazd & 0.808 & 0.871 & 0.600 & - & - & - \\
\hline
\end{tabular}

(DMU14) and Azerbaijan (DMU1) with the values of $0.953)$ are the most efficient subsystems in this section. According to the results of the overall efficiencies and subsystems efficiencies for this supply chain, Mazandaran, Gilan, and Azerbaijan Companies were superior in terms of performance.

For optimization, inefficiency sources have to be identified according to these results. Next, their performance should be improved properly by authorities using the slack and surplus values of units which have been shown in Table 6 for 2011. For other years, the process is the same; however, to prevent extensive amounts of data, only the latest year's values have been presented.

These results also were obtained by Lingo Software according to Eq. (8). As can be seen in Table 6, even for most efficient units, increasing outputs and/or decreasing inputs according to $s+$ and $s$ - values should be taken into account since these units are not quite efficient. For instance, the results for Mazandaran (DMU14) show that, for optimizing, this unit needs to decrease the $x_{3 j 1}$ (imported energy from neighboring power companies) and $x_{4 j 1}$ (labor of transmission section) to 1771 and 138, respectively. In addition, it is required to increase the $z_{1 j 3}^{1}$ (total sold energy of the first distribution company) and $z_{2 j 3}^{1}$ (number of customers of the first distribution company) to 5453 and 143, respectively. However, for $x_{5 j 3}^{2}$, the calculated value is not significant, and this index does not need any essential change. For intermediate indexes like $z_{1 j 1}$ (generated energy), which is, simultaneously, output for generation section and input for transmission section, the calculated slack or surplus values should be considered in one of the sections. For example, the value of this index for Azerbaijan (DMU1) is 9280, which means 9280 units increase in generation section as an output or 9280 units decrease in transmission section as an input.

\section{Conclusion}

Many methods have been proposed for evaluating performance of supply chain subsystems. However, in practice, the subsystems of each system are correlated and have interactions with each other throughout the system. Therefore, for performance assessment, the utilized methods must be able to model these interactions all together at the same time. Evaluating performance of the whole supply chain including its subsystems and interactions between them as an integrated system will be possible by using NDEA models. This research provided a comprehensive NDEA/AR model to evaluate energy supply chain including subsystems of generation, transmission and distribution in which experts' viewpoints have ideal effects on the results. In other words, results have been calculated by combining experts' opinions and NDEA/AR method, and thus, are more scientific and reliable. In this regard, not only experts' intelligence are properly utilized, but also entering these directions to the model, as assurance region, enhances the discriminative power of NDEA model and prevents 
Table 6. The slacks and surpluses values for the NDEA/AR in 2011.

\begin{tabular}{|c|c|c|c|c|c|c|c|c|c|c|c|c|c|c|c|c|}
\hline & 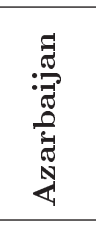 & 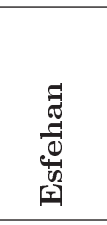 & 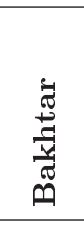 & 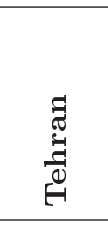 & 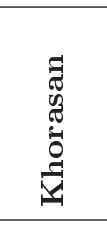 & 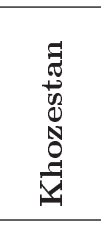 & $\begin{array}{l}\underset{\Xi}{\Xi} \\
\stackrel{\widetilde{J}}{\Xi} \\
\end{array}$ & 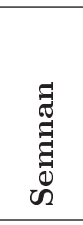 & 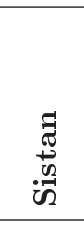 & 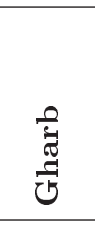 & $\begin{array}{l}n \\
\frac{n}{\pi} \\
\text { T. } \\
\end{array}$ & 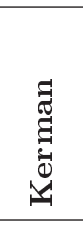 & 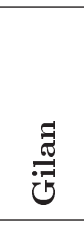 & 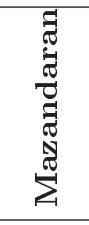 & 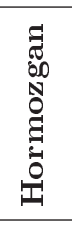 & $\begin{array}{l}\text { ָే } \\
\text { స్ } \\
\end{array}$ \\
\hline$Z_{1 j 0}$ & 0 & 0 & 0 & 0 & 0 & 0 & 0 & 0 & 0 & 0 & 0 & 0 & 0 & 0 & 0 & 0 \\
\hline$Z_{2 j 0}$ & 0 & 0 & 0 & 0 & 0 & 0 & 0 & 0 & 0 & 0 & 0 & 0 & 0 & 0 & 0 & 0 \\
\hline$Z_{1 j 1}$ & 9280 & 13465 & 0 & 21018 & 7746 & 5742 & 0 & 0 & 1517 & 5105 & 0 & 1639 & 0 & 0 & 0 & 0 \\
\hline$X_{1 j 1}$ & 4550 & 6258 & 0 & 21334 & 9698 & 15446 & 0 & 34 & 0 & 3312 & 4124 & 0 & 2310 & 0 & 0 & 0 \\
\hline$X_{2 j 1}$ & 0 & 2529 & 630 & 0 & 1268 & 497 & 349 & 0 & 0 & 3212 & 160 & 0 & 0 & 0 & 0 & 0 \\
\hline$X_{3 j 1}$ & 5979 & 5377 & 4463 & 4505 & 10043 & 3498 & 0 & 152 & 778 & 4751 & 5973 & 0 & 1593 & 1771 & 326 & 0 \\
\hline$X_{4 j 1}$ & 454 & 0 & 45 & 562 & 340 & 379 & 85 & 3 & 84 & 153 & 71 & 0 & 63 & 138 & 73 & 29 \\
\hline$Y_{1 j 1}$ & 0 & 0 & 0 & 0 & 0 & 0 & 0 & 0 & 0 & 0 & 0 & 0 & 0 & 0 & 0 & 0 \\
\hline$Y_{2 j 1}$ & 0 & 0 & 0 & 0 & 0 & 0 & 0 & 0 & 485 & 655 & 0 & 0 & 0 & 0 & 0 & 0 \\
\hline$z_{1 j 2}^{1}$ & 0 & 0 & 1199 & 0 & 0 & 2594 & 0 & 0 & 0 & 0 & 3265 & 0 & 0 & 0 & 0 & 0 \\
\hline$z_{1 j 2}^{2}$ & 0 & 5198 & 0 & 1490 & 0 & 2461 & 0 & 0 & 0 & 0 & 0 & 0 & 74 & 0 & 479 & 163 \\
\hline$z_{1 j 2}^{3}$ & 0 & 0 & 0 & 0 & 19 & 0 & 0 & 0 & 0 & 0 & 0 & 0 & 94 & 0 & 606 & 206 \\
\hline$z_{1 j 2}^{4}$ & 0 & 52 & 0 & 0 & 0 & 0 & 0 & 0 & 0 & 225 & 907 & 0 & 0 & 0 & 0 & 0 \\
\hline$x_{5 j 3}^{1}$ & 0 & 0 & 0 & 0 & 0 & 0 & 0 & 0 & 0 & 0 & 0 & 0 & 0 & 0 & 0 & 0 \\
\hline$x_{5 j 3}^{2}$ & 441 & 0 & 0 & 0 & 0 & 0 & 0 & 0 & 0 & 0 & 0 & 0 & 0 & 0.7 & 0 & 0 \\
\hline$x_{5 j 3}^{3}$ & 0 & 0 & 0 & 0 & 0 & 66 & 0 & 0 & 0 & 0 & 0 & 0 & 0 & 0 & 0 & 0 \\
\hline$x_{5 j 3}^{4}$ & 0 & 0 & 0 & 0 & 0 & 0 & 0 & 0 & 0 & 0 & 0 & 0 & 0 & 0 & 0 & 0 \\
\hline$z_{1 j 3}^{1}$ & 4239 & 0 & 0 & 10107 & 2913 & 1953 & 895 & 1100 & 588 & 1884 & 8648 & 2131 & 3530 & 5453 & 0 & 0 \\
\hline$z_{2 j 3}^{1}$ & 91 & 0 & 218 & 0 & 0 & 192 & 0 & 38 & 0 & 0 & 196 & 211 & 0 & 143 & 615 & 0 \\
\hline$z_{1 j 3}^{2}$ & 2294 & 1345 & 1713 & 1242 & 3940 & 0 & 0 & 0 & 0 & 742 & 278 & 0 & 0 & 0 & 0 & 0 \\
\hline$z_{2 j 3}^{2}$ & 21 & 344 & 104 & 125 & 456 & 0 & 0 & 0 & 0 & 0 & 75 & 0 & 0 & 0 & 0 & 0 \\
\hline$z_{1 j 3}^{3}$ & 88 & 0 & 0 & 0 & 536 & 0 & 0 & 0 & 0 & 0 & 0 & 0 & 0 & 0 & 0 & 0 \\
\hline$z_{2 j 3}^{3}$ & 0 & 0 & 0 & 0 & 71 & 16 & 0 & 0 & 0 & 0 & 0 & 0 & 0 & 0 & 0 & 0 \\
\hline$z_{1 j 3}^{4}$ & 112 & 0 & 0 & 0 & 0 & 0 & 0 & 0 & 0 & 0 & 0 & 0 & 0 & 0 & 0 & 0 \\
\hline$z_{2 j 3}^{4}$ & 0 & 0 & 0 & 0 & 0 & 0 & 0 & 0 & 0 & 0 & 0 & 0 & 0 & 0 & 0 & 0 \\
\hline
\end{tabular}

ignoring some indexes' roles in calculating efficiency score. Another important capability of the proposed model was that it calculated efficiency of the whole system and subsystems simultaneously. Calculated scores for subsystems' efficiencies will identify inefficient units. Subsequently, optimization measurements can be done within these subsystems by analyzing slack and surplus values. Finally, if these actions were done systematically for all of the inefficient units, an efficient supply chain will be achievable. Reaching such results is the goal of all sectors, and this model has the ability to produce a brief and monolithic data for authorities to detect and optimize weaknesses in the supply chain. Furthermore, according to the differences in available resources, geographical conditions and current policies between countries, weights of index may not be the same for all regions. However, they can be defined based on decision-makers' preferences. Owing to flexibility of NDEA, the presented model is highly adaptable and can be implemented for every supply chain. Considering these issues, it seems fair to suggest that the presented model can be used as a framework for evaluating supply chain in each system regardless of its size and location; however, it is more effective in policy and decision making in bigger scales.

\section{Acknowledgement}

The authors are cordially grateful for the anonymous reviewers, as this paper could not have reached this quality without their constructive comments and useful remarks.

\section{References}

1. Panjeshahi, M.H.P., Harati, F. and Nouzari, M.M. "Improving energy efficiency in natural gas refineries, using energy analysis", Chem. Eng. Trans., 21, pp. 121-126 (2010).

2. Ostadi, H. and Fatehi, J. "The effect of energy con- 
sumption on economic growth in industrialized G8 countries", Int. J. Acad. Res. Bus. Soc. Sci, 4(5), pp. 355-369 (2014).

3. Zhou, P., Ang, B.W. and Zhou, D.Q. "Measuring economy-wide energy efficiency performance: A parametric frontier approach", Appl. Energy, 90(1), pp. 196-200 (2012).

4. Hu, J.-L., Lio, M.-C., Yeh, F.-Y. and Lin, C.-H. "Environment-adjusted regional energy efficiency in Taiwan", Appl. Energy, 88(8), pp. 2893-2899 (2011).

5. Wang, Z.-H., Zeng, H.-L., Wei, Y.-M. and Zhang, Y.-X. "Regional total factor energy efficiency: An empirical analysis of industrial sector in China", Appl. Energy, 97(0), pp. 115-123 (2012).

6. Yadav, V.K., Padhy, N.P. and Gupta, H.O. "A micro level study of an Indian electric utility for efficiency enhancement", Energy, 35(10), pp. 4053-4063 (2010).

7. See, K.F. and Coelli, T. "An analysis of factors that influence the technical efficiency of Malaysian thermal power plants", Energy Econ., 34(3), pp. 677685 (2012).

8. Alizadeh, R., Majidpour, M., Maknoon, R. and Shafiei Kaleibari, S. "Clean development mechanism in Iran: Does it need a revival?", Int. J. Global Warm. (In Press).

9. Jaraite, J. and Di Maria, C. "Efficiency, productivity and environmental policy: A case study of power generation in the EU", Energy Econ., 34(5), pp. 15571568 (2012).

10. Solmes, L. Real Time Energy Infrastructure Investment and Risk Management. Energy Efficien, L. Solmes, Springer Netherlands, pp. 1-212 (2009).

11. Omrani, H., Gharizadeh Beiragh, R. and Shafiei Kaleibari, S. "Performance assessment of Iranian electricity distribution companies by an integrated cooperative game data envelopment analysis principal component analysis approach", Int. J. Elect. Power Energy Syst., 64(0), pp. 617-625 (2015).

12. Fallahi, A., Ebrahimi, R. and Ghaderi, S.F. "Measuring efficiency and productivity change in power electric generation management companies by using data envelopment analysis: A case study", Energy, 36(11), pp. 6398-6405 (2011).

13. Vazhayil, J.P. and Balasubramanian, R. "Optimization of India's power sector strategies using weightrestricted stochastic data envelopment analysis", Energy Policy, 56(0), pp. 456-465 (2013).

14. Pardo Martínez, C. "Energy efficiency development in German and Colombian non-energy-intensive sectors: a non-parametric analysis", Energy Efficien., 4(1), pp. 115-131 (2011).

15. Liang, Q.-M., Fan, Y. and Wei, Y.-M. "The effect of energy end-use efficiency improvement on China's energy use and $\mathrm{CO}_{2}$ emissions: a CGE model-based analysis", Energy Efficien., 2(3), pp. 243-262 (2009).
16. Bas, E. "The integrated framework for analysis of electricity supply chain using an integrated SWOTfuzzy TOPSIS methodology combined with AHP: The case of Turkey", Int. J. Elect. Power Energy Syst., 44(1), pp. 897-907 (2013).

17. Huang, Y.-J., Chen, K.-H. and Yang, C.-H. "Cost efficiency and optimal scale of electricity distribution firms in Taiwan: An application of metafrontier analysis", Energy Econ., 32(1), pp. 15-23 (2010).

18. Charnes, A., Cooper, W.W. and Rhodes, E. "Measuring the efficiency of decision making units", Eur. J. Oper. Res., 2(6), pp. 429-444 (1978).

19. Färe, R. and Grosskopf, S. "Network DEA", Socio. Econ. Plan. Sci., 34(1), pp. 35-49 (2000).

20. Castelli, L., Pesenti, R. and Ukovich, W. "DEA-like models for efficiency evaluations of specialized and interdependent units", Eur. J. Oper. Res., 132(2), pp. 274-286 (2001).

21. Lewis, H.F. and Sexton, T.R. "Network DEA: efficiency analysis of organizations with complex internal structure", Comput. Oper. Res., 31(9), pp. 1365-1410 (2004).

22. Prieto, A.M. and Zofío, J.L. "Network DEA efficiency in input-output models: With an application to OECD countries", Eur. J. Oper. Res., 178(1), pp. 292-304 (2007).

23. Bai-Chen, X., Ying, F. and Qian-Qian, Q. "Does generation form influence environmental efficiency performance? An analysis of China's power system", Appl. Energy, 96(0), pp. 261-271 (2012).

24. Chen, C. and Yan, H. "Network DEA model for supply chain performance evaluation", Eur. J. Oper. Res., 213(1), pp. 147-155 (2011).

25. Kao, C. "Efficiency decomposition in network data envelopment analysis: A relational model", Eur. J. Oper. Res., 192(3), pp. 949-962 (2009).

26. Kao, C. and Hwang, S.-N. "Efficiency measurement for network systems: IT impact on firm performance", Decis. Support Syst., 48(3), pp. 437-446 (2010).

27. Tone, K. and Tsutsui, M. "Network DEA: A slacksbased measure approach", Eur. J. Oper. Res., 197(1), pp. 243-252 (2009).

28. Hsieh, L.-F. and Lin, L.-H. "A performance evaluation model for international tourist hotels in Taiwan-An application of the relational network DEA", Int. J. Hosp. Manag., 29(1), pp. 14-24 (2010).

29. Matthews, K. "Risk management and managerial efficiency in Chinese banks: A network DEA framework", Omega, 41(2), pp. 207-215 (2013).

30. Zhao, Y., Triantis, K., Murray-Tuite, P. and Edara, P. "Performance measurement of a transportation network with a downtown space reservation system: A network-DEA approach", Transp. Res. Part E: Logist. Transp. Rev., 47(6), pp. 1140-1159 (2011). 
31. Wang, Y.-M., Chin, K.-S. and Poon, G.K.K. "A data envelopment analysis method with assurance region for weight generation in the analytic hierarchy process", Decis. Support Syst., 45(4), pp. 913-921 (2008).

32. Wang, Y.-M. and Chin, K.-S. "A new data envelopment analysis method for priority determination and group decision making in the analytic hierarchy process", Eur. J. Oper. Res., 195(1), pp. 239-250 (2009).

33. Cooper, W.W., Seiford, L.M. and Tone, K., A Comprehensive Text with Models, Applications, References and DEA-Solver Software. Data Envelopment Analysis, Springer US: 1-490 (2007).

34. Azadeh, A., Ghaderi, S.F., Omrani, H. and Eivazy, H. "An integrated DEA-COLS-SFA algorithm for optimization and policy making of electricity distribution units", Energy Policy, 37(7), pp. 2605-2618 (2009).

\section{Biographies}

Saeed Shafiei Kaleibari received his BSc degree in Industrial Engineering from Payam Noor University of Tabriz, Iran. His research interests include supply chain management and logistics, optimization methods, efficiency and productivity analysis (DEA, SFA, etc.), decision support systems, multiple criteria decision making, game theory, simulation, renewable energies and climate policy. He has also several publications in international journals.

Ramin Gharizadeh Beiragh received his BSc and MSc degrees in Industrial Engineering from Payam Noor University of Tabriz, Iran, and from Urmia
University of Technology, Urmia, Iran respectively. His research interests are multiple criteria decision making, dame theory, efficiency and productivity analysis (DEA, SFA, etc.), production planning, and control. He has several publications in international journals.

Reza Alizadeh received his BSc degree in Industrial Engineering from Urmia University of Technology, Urmia, Iran, and holds a Master degree in Technology Foresight from Amirkabir University of Technology (AUT), Tehran, Iran. He has been honored through receipt of the distinguished Master's Thesis Award of AUT in 2014. He is a researcher at Future Studies Research Institute of AUT and Sustainability Office of AUT. Also, he is a member of Iranian National Elite Foundation. His research interests include energy and climate policy, strategic management, technology policy and foresight, decision-making, and sustainability. He has more than ten papers in international journals and conferences.

Maghsud Solimanpur is a Professor of Industrial Engineering in the Faculty of Engineering at Urmia University, Urmia, Iran. He received his BSc and MSc degrees from Sharif University of Technology in 1994 and 1997, respectively. Subsequently, he received his $\mathrm{PhD}$ from the Indian Institute of Technology Delhi, New Delhi, India, in 2003. His research interests are design of cellular manufacturing systems, facilities planning and layout, optimization of manufacturing processes, meta-heuristics, etc. He has published more than 100 papers in different journals of repute and conferences. 